\title{
An Application of PDA and Barcode Technology for the Improvement of Information Management in Construction Projects
}

\author{
Se-Wook Oh ${ }^{1}$, Hee-Jin Chang ${ }^{2}$, Young-Suk Kim ${ }^{3}$, \\ Jun-Bok Lee ${ }^{4}$ and Han-Soo Kim ${ }^{5}$ \\ ${ }^{1} \mathrm{Ph} . \mathrm{D}$. Candidate, Inha University, Incheon, Korea \\ ${ }^{2}$ Graduate Research Assistant, Inha University, Incheon, Korea \\ ${ }^{3}$ Assistant Professor, Inha University, Incheon, Korea \\ ${ }^{4}$ Assistant Professor, Hongik University, Incheon, Korea \\ ${ }^{5}$ Assistant Professor, Sejong University, Incheon, Korea \\ E-mail: youngsuk@inha.ac.kr
}

\begin{abstract}
Work information in a construction project can be effectively used to analyze the project status related to schedule, cost, productivity etc. The purpose of this research is to develop a computer-based system using PDA and barcode technology to measure and monitor the amount of workforce resources and productivity. The developed system is expected to effectively assist schedule planning and management for present and prospective construction projects.
\end{abstract}

KEYWORDS: PDA, Barcode, ASIMO, Labor management, Productivity, Schedule management

\section{INTRODUCTION}

Work information can be used to accumulate construction information, analyze project status and management system, and design a new similar project plan. This information can also be used to make productivity data, and these productivity data can be as well used to analyze the relationship between 'as planned' and 'as built' in scheduling management of a project. It is common that site engineers' experience during the project period is a critical factor in terms of collecting and managing a great deal of construction information, but relying on the only site engineers' experience has been an obstacle in the effort to improve construction efficiency and accumulate construction data. Such a condition may be the result of the lack of systems and IT tools for collecting workers' data, which can be directly applied to construction management.

The purpose of this paper is to develop a computer-based system (named 'Advanced Site Information Management Organizer': ASIMO) for measuring and monitoring the amount of workforce resources, work materials, and productivity data by applying PDA and barcode technology. The developed system is expected to assist schedule planning and management effectively for present and prospective construction projects. The scope of this research is limited to structure work in apartment buildings. To make a ASIMO system, this research begins by describing the specific characters of the structure work as well as performing the literature review. The developed ASIMO system is then illustrated in this study. This research validates the effectiveness of the ASIMO system by using data which were collected in construction field. Finally, conclusions are made concerning the value and applicability of the ASIMO system.

\section{THEORETICAL CONSIDERATION ON THE INFORMATION MANAGEMENT OF CONSTRUCTION PROJECTS}

2.1 The Nature of Structure Work in Apartment Building Construction

Construction of apartment buildings includes works related to the earth, foundation, structure, finishing and others. Among these works, the structure work, as a primary work making up $60 \%$ of all processes, is a part of the critical path. The characteristics of the structure work in the construction of apartment buildings include the following.

1) Repetitive activities: The structure work is chiefly composed of vertically repetitive activities. It is thus not difficult to measure and analyze the labor productivity statistically.

2) Composition of diverse activities: The structure work consists of several activities such as the form work, the steel work, the concrete work, which are carried out by specific teams. So, it is possible to measure a worker's productivity in each activity.

3) Limited workspace: In the case of the structure work, it is easy to measure the worker's productivity for each floor of each building because of the characteristics of the construction style, which is 
performed vertically, step by step.

Consequently, the division of activities can be easily made, and it can be possible to collect data regarding of workers' working time in each activity and the amount of performed work. In addition, these collected data could be analyzed and could be changed into a variety of historical data.

\subsection{Needs for the Information Management in a Construction Project}

The construction information management in structure work performed for apartment building construction is widely known to be comparatively easy. However, because a construction plan are formulated by being based on a construction manager's experience rather than on exact historical data, such a plan often has problems such as frequent changes in the resource flow and the schedule. The problems of the information management system in Korean construction projects are summarized in Table 1.

Table 1. Problems of the Information Management System in Korean Construction Projects

\begin{tabular}{|c|c|}
\hline Factors & Contents \\
\hline $\begin{array}{l}\text { Lack of } \\
\text { documentation } \\
\text { system for the } \\
\text { construction } \\
\text { information } \\
\text { management }\end{array}$ & $\begin{array}{l}\text { The existing documents such } \\
\text { as daily reports are not usually } \\
\text { made timely, and largely } \\
\text { depend on a site engineer's } \\
\text { experience } \\
\text { In addition, most of these } \\
\text { documents are generally } \\
\text { thrown away after one-time } \\
\text { use. }\end{array}$ \\
\hline $\begin{array}{l}\text { Poor computer- } \\
\text { based system }\end{array}$ & $\begin{array}{l}\text { Since most programs for } \\
\text { construction management are } \\
\text { mainly made only for plan of a } \\
\text { new construction project, it is } \\
\text { difficult to measure and } \\
\text { monitor the actual } \\
\text { construction process }\end{array}$ \\
\hline $\begin{array}{l}\text { Lack of data for } \\
\text { the labor and } \\
\text { productivity } \\
\text { management }\end{array}$ & $\begin{array}{l}\text { Predicting the schedule of } \\
\text { each activity requires labor } \\
\text { and productivity management } \\
\text { data, but both a method to } \\
\text { collect these data and a system } \\
\text { to analyze them do not exist at } \\
\text { the present. }\end{array}$ \\
\hline $\begin{array}{l}\text { Process focused } \\
\text { on only the } \\
\text { amount of } \\
\text { performed work }\end{array}$ & $\begin{array}{l}\text { To calculate the rate of } \\
\text { progress, data such as a } \\
\text { worker's working time, the } \\
\text { amount of performed work } \\
\text { should be considered, but only } \\
\text { the amount of performed work } \\
\text { is considered in actual } \\
\text { construction management. }\end{array}$ \\
\hline
\end{tabular}

For solving these problems, the following process is required.

- Determine a method to collect data from each activity during construction.

- Collect data of each activity in the field.

- Calculate the productivity data by applying the data, which are workers' working time and the amount of performed work in a day, collected in each activity.

- link the productivity data with the scheduling management.

- Calculate a variety of productivity figures by using the productivity data.

- Accumulate the historical data for construction management

To collect the productivity data on the time and amount of each activity in the field, the most effective method is using IT tools.

\subsection{Current Related Research Issues}

There have been major advances in using IT tools to collect data for construction project management over the past few years.

(1) Trend and Application of Korean IT Technology Kang(1995) developed a system for making a plan and easily managing field inventory by exactly showing the materials and assembly situation. The information on the materials to which a bar-code is attached is input into a computer and then, this information is transmitted through the LAN to a computer in the head office. By this process, a construction manager in the head office can have a good understanding of both the material production process in the factory and the construction process in the field.[1]

Lee(1997) developed a system which can increase the efficiency and speed of works done for construction. The system gives a construction manager the images presenting the progress of construction. A construction manager in the head office can have a good understanding of the construction progress from start to present by watching photographs on a computer screen containing the data on the construction site.[2]

$\operatorname{Lim}(2000)$ pointed out the need to change the existing worker checking system. He developed a system which allows a construction manager to recognize the site engineers' and workers' work time. In the system, a bar-code reader, which is installed in a field office, could collect the workers' bar-code data allocated to each of the workers.[3]

(2) Trend and Application of Foreign IT Technology

Calibre2000 (BRE, 2000) proposed a method for measuring the productivity of work and the situation of a construction by using a PDA and a digital camera. These IT tools can be used to collect pictures displaying the progress of performed work and data 
on the work duration of workers. Then, by reviewing the data on labor productivity and the performance collected by the IT tools, a construction manager can receive a better understanding about the current construction situation and the productivity of each work.[4]

Lin(2001) proposed a model to support communication between a construction group (e.g. people who are at a construction site, a field office and a head office) and the other groups (e.g. a subcontractor, a material supplier, a equipment supplier, an owner, an architect and a consultant). This model collects construction site data. These data can be collected by using a PDA.[5] Like the researches and practices illustrated above, although IT tools have been used in construction management over the years, they have still been insufficient in terms of users' convenience, and limited in the number of data targets that must be collected for construction management.

Consequently, this study developed a system for construction management by connecting labor management and productivity management with scheduling management of a construction project and by applying the data collected from IT tools in a construction site. The following data must be collected:

- Workers' time in office and time out of office.

- Workers' working time in each activity.

- The amount of materials used in the work performed daily in each activity.

\section{METHODOLOGY}

\subsection{Methodology to Collect Data in the Construction} Site

This paper proposed a methodology, illustrated in Fig. 1, for collecting data in the construction field by using IT tools.

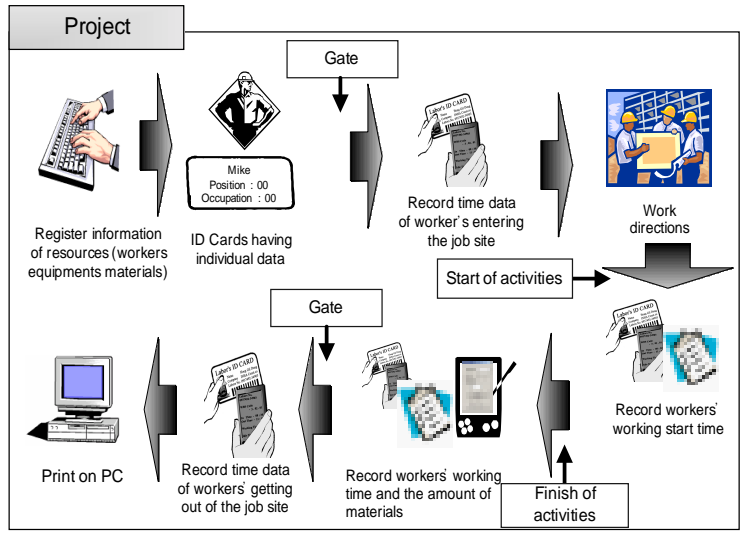

Figure 1. Process for Collecting Data in the Construction Field

To collect data, a site engineer would input a worker's data into a PC on site and provide each worker with a bar-coded ID card. At the beginning of the day, when the workers enter the gate, the barcode would be scanned by a PDA to which a barcode reader is attached. This would give a manager a list of the workers who are on the jobsite and the time when the workers entered the jobsite. An inspector would record the time data related actual working time of each worker in each activity in the PDA. Moreover, at the end of the day, the inspector would record the amount of materials used in the work performed daily in each activity, and the workers would be checked out when the barcode reader scans their barcodes at the exit gate.

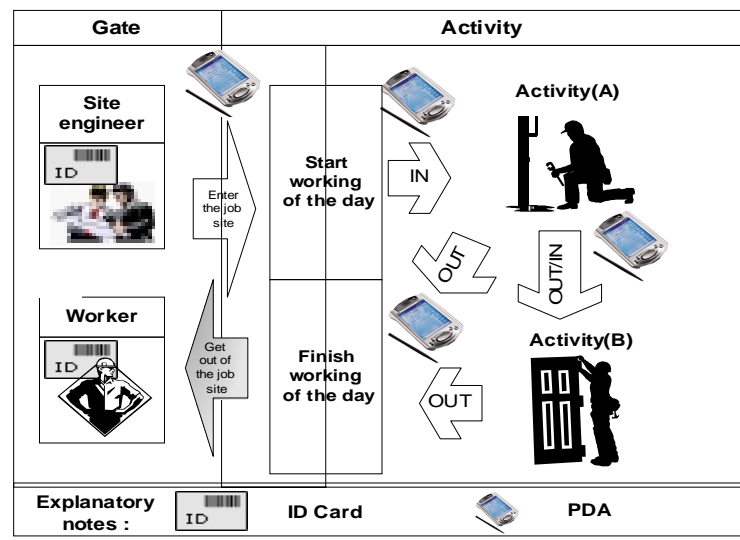

Figure 2. Process for Collecting Data of Workers' Working Time

The data collected through this process would be changed into the data which can be used in the labor, productivity, scheduling management. The detail of the process for collecting data of the workers' working time is illustrated in Fig. 2. First, to collect the data on the time when site managers and workers enter the jobsite, site managers and workers would be provided with ID cards including a barcode(step 1) and then, at the beginning of the day, their barcodes would be scanned by a PDA(step 2). To collect the data on the workers' working time for each activity, the inspector would record the time by using a PDA for the workers when the site manager inputs them into each activity (step 3). At the end of the day, the inspector would also record the time by using the same IT tool (step 4). Moreover, if workers moved among the activities, the inspector could record data of the workers' finish time in the prior activity and start time in the new activity. At the end of the last work of the day, the inspector would record data of the workers' finish time of the last activity (step 5). Lastly, at the end of the day, the time at which the workers' leave the site would be checked out when the barcode reader scans their barcodes at the exit gate (step 6).

\subsection{Design of User Interface for PDA}

Fig. 3 shows the design of the user interface for PDA to collect the data on workers' jobsite entrance time, working time of activities, and the amount of performed work in each activity. The User interface 
in Fig. 3(a) collects the jobsite entrance time data. The site engineer can use the collected data to check the worker's attendance, and the data can be also used to print daily reports. The user interface in Fig. 3(b) is to select the on-going activity of the day. These activity data can be transmitted from a server to the ASIMO system. After the inspector selects the activity of the day on the PDA screen, he would record the data on workers' working time in that activity. At the end of the work, the inspector could directly record the figures on the amount of materials used in the work performed of the day in each activity or input the percentage of the amount. The data collected in this process can be changed in the ASIMO system into fundamental data, which are useful in the labor, productivity, and schedule management.

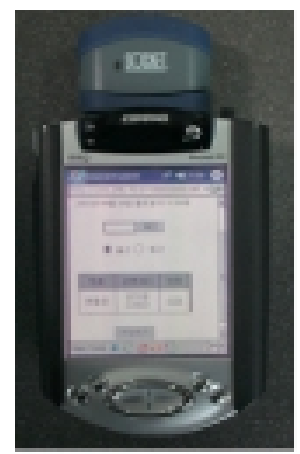

(a) Collect Time Data of Workers' Attending the Jobsite

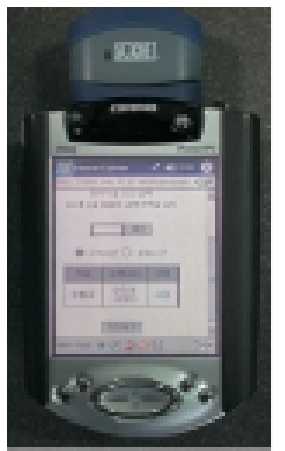

(c) Collect Time Data of Workers' Working

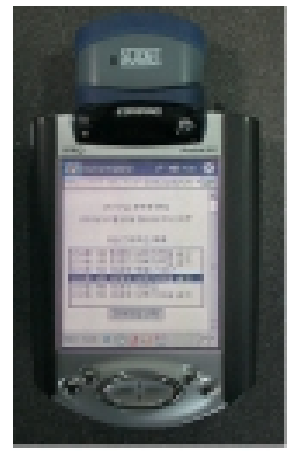

(b) Select an Activity

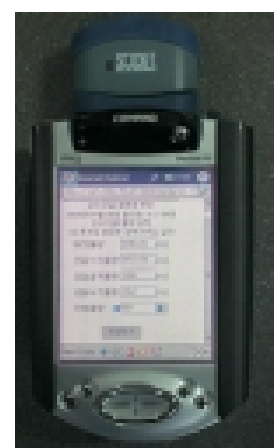

(d)

Record

Amount of Performed Work of the Day
Figure 3. User Interface for PDA

\section{SYSTEM IMPLEMENTATION}

\subsection{Surroundings of Implementation for ASIMO System}

ASIMO system consists of the DBMS (database management system)-based server, wireless internetbased PDA client and a web-based PC client. The PDA is highly portable and convenient for entering data any where, any time.

Therefore, this IT tool can be the best tool to collect data such as workers' time in office and out of office, the start and finish time of workers' working in each activity, and the amount of materials used in the work performed in each activity. The user Interface of the web based-PC client and PDA were designed so that the user can conveniently access the system under the internet network environment, and the user interface of PDA could be transmitted by wireless LAN in real time. The data transmission in the ASIMO system is shown in Fig. 4.

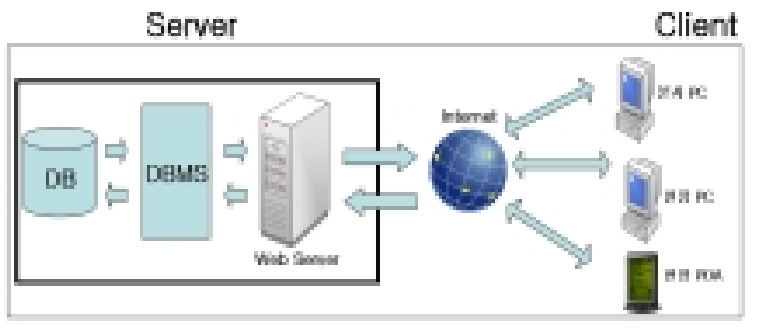

Figure 4. Data Transmission in the ASIMO System

Table 2. shows the developing environment of the ASIMO system.

Table 2. Developing Environment of ASIMO

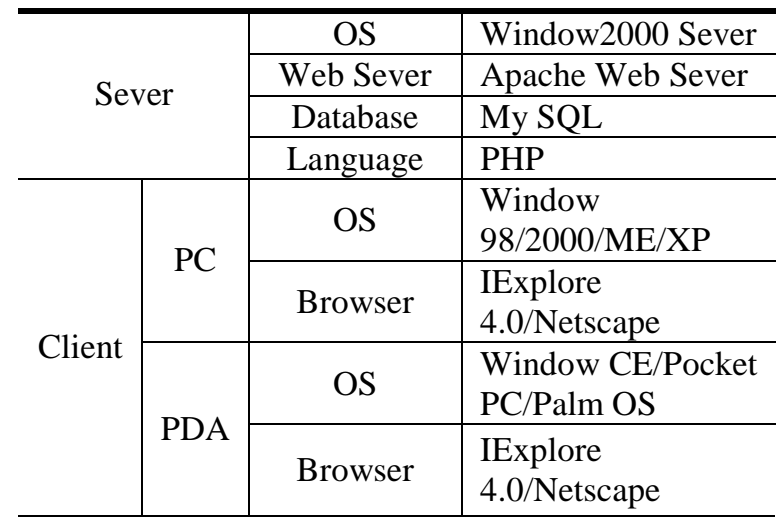

\subsection{Implementation of the ASIMO System}

To verify and test the possibility of application of the ASIMO system to the construction field, the data on 4 apartment buildings on which the structure work was performed were collected and applied to the ASIMO system.

\section{(1) Screen of the Input Module}

The input module is a function by which fundamental data can be input to operate the system. Using a PDA, this module can make data collecting easy, and help the printing of the collected data in the other function modules. Fig. 5 shows the input data screen for the planned activities. In this screen, the data such as the planned amount of materials, the planned $\mathrm{MH}$ (man-hour), the planned productivity, the planned start and finish date of every activity are entered. Once the construction starts, the planned activity data can be influenced by a variety of factors such as the changes in the work, supply plan and the decline of productivity of the several activities. Site 
manager can not use the planned activity data to collect the activity information on the PDA. Shown as Fig. 6, the site engineer should select activities to be performed in the next day by considering the field situation and work plan. These selected data would be displayed on the PDA screen for the user's convenience.

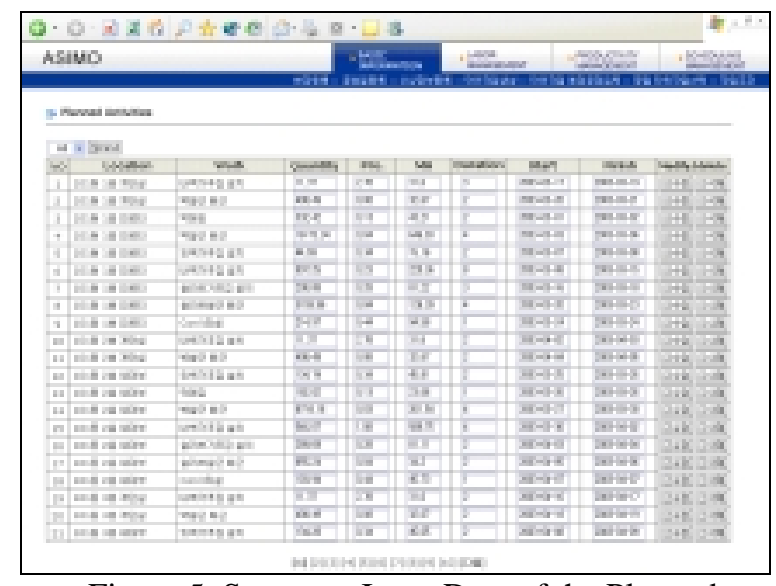

Figure 5. Screen to Input Data of the Planned Activities

Fig. 7 shows the screen for entering a worker's individual data. In this screen, a worker's personal data such as name, company, position, skilled/nonskilled worker, and the barcode number is entered.

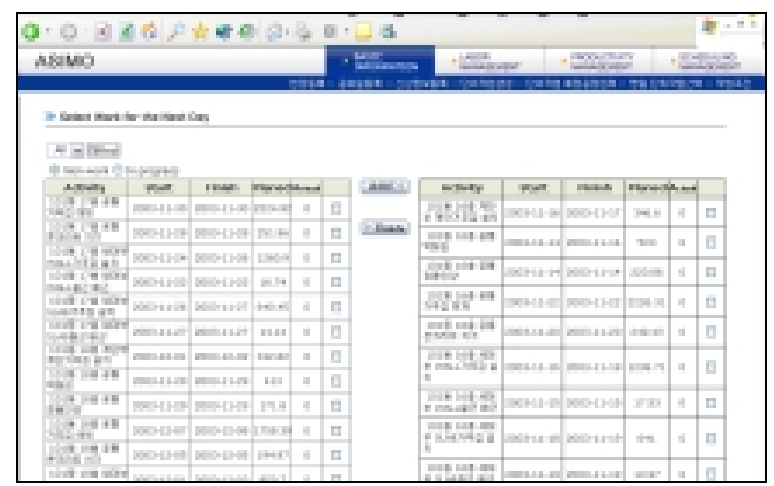

Figure 6. Screen to Select Activities to be Performed Next Day

(2) Screen of the Labor Management Module

Fig. 8 is the screen that shows the status of the workers' time in office and time out of office collected by a PDA. This screen helps the site engineer to identify the workers who have entered the job site within a certain period. Such information can be useful to calculate the labor cost.

Fig. 9 shows the screen the in/out times of the workers in activities performed on a specific date. In this screen, each worker's data such as name, position, type of occupation, the names of the activities in which the worker has worked, and in/out time for the start/ finish for the work performed by the worker can be printed.

These data could also be printed in the productivity and scheduling management module and can be used in the analysis of the result of the project.

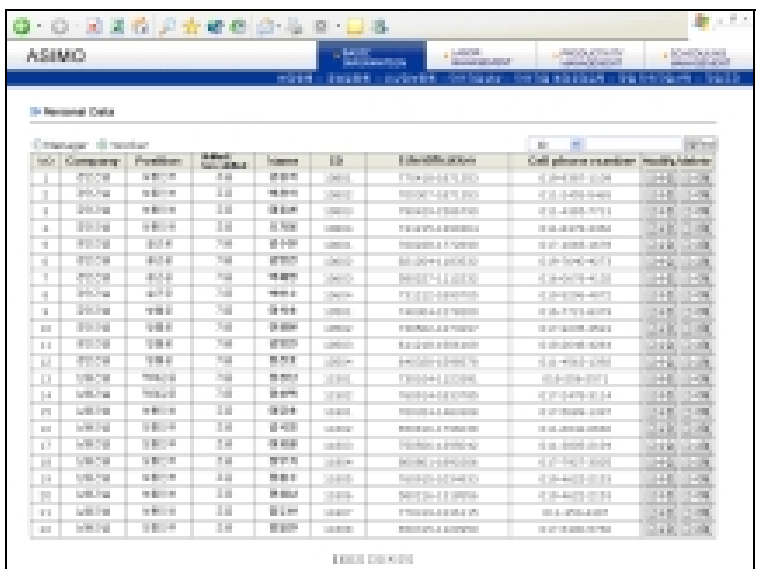

Figure 7. Screen to Input Workers' Individual Data

(3) Screen of the Productivity Management Module Fig. 10 is the screen showing the productivity data of the activities performed on a specific date. These productivity data can be calculated by using the data on the workers' working time in each activity, and the amount of the performed work. The productivity data can largely be classified into the productivity in an activity (unit/MH) and the actual time worked in an activity(MH/unit). Therefore, as shown in Fig. 10, the productivity in an activity of the wall form work on the house side, the 4th floor, No.101 is 3.12, and the amount of performed work per worker and per hour in an activity is 0.46 . The value of 3.12 means that one worker can perform the work on an area of $3.12 \mathrm{~m}^{2}$ for an hour; on the other hand, the 0.32 means that 0.46 man-hour is needed to perform work on an area of $1 \mathrm{~m}^{2}$. Moreover, the inspector can record any productivity problems of an activity in the PDA to provide exact productivity data.

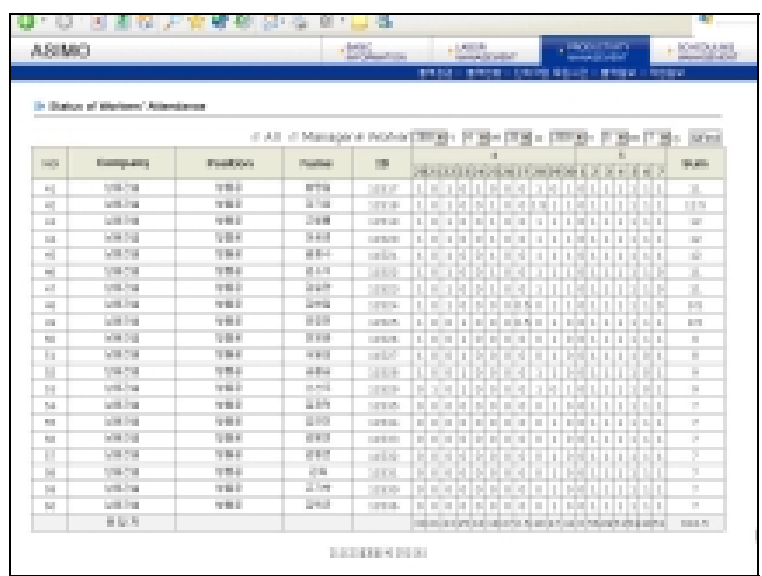

Figure 8. Screen of the Situation of Workers' Attending Time within a Certain Period

The productivity data can be accumulated and output according to various criteria such as the activity, the building, and the floor. Such data would be useful in the productivity analysis and final 
project assessment.

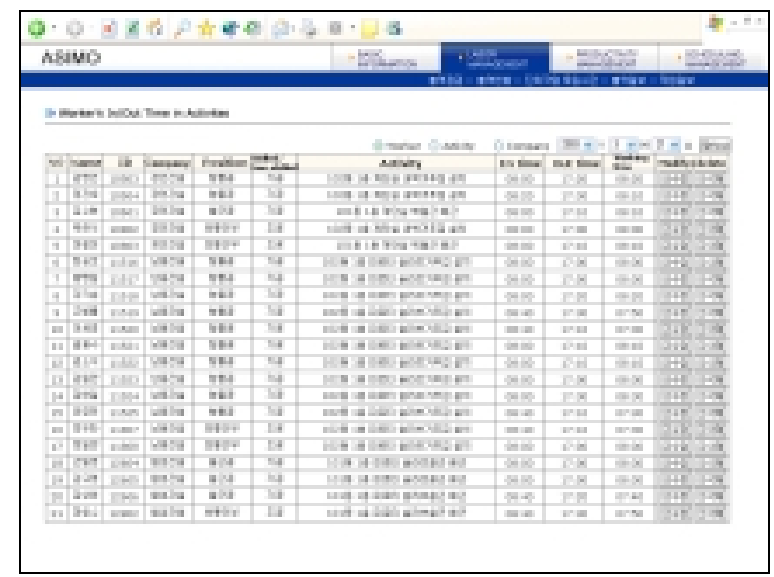

Figure 9. Screen of the Situation of Workers' In/Out Time in Each Activity

(4) Screen of the Scheduling Management Module

In the scheduling management module of the ASIMO system, the historical data for scheduling management and the rate of progress can be represented by applying data on the workers' working time, the amount of performed work, and the productivity related to the activities. Fig. 11 shows the screen of the historical data for scheduling management. The data printed on this screen are the planned start/finish date, the actual start/finish date, the planned amount of work, the actual amount of performed work, the anticipated duration, and the variation of the actual duration regarding every performed activity. These data, calculated by applying the relationship between the data on the workers' working time and the amount of performed work collected from the PDA, could be used as supporting data in actual scheduling management.

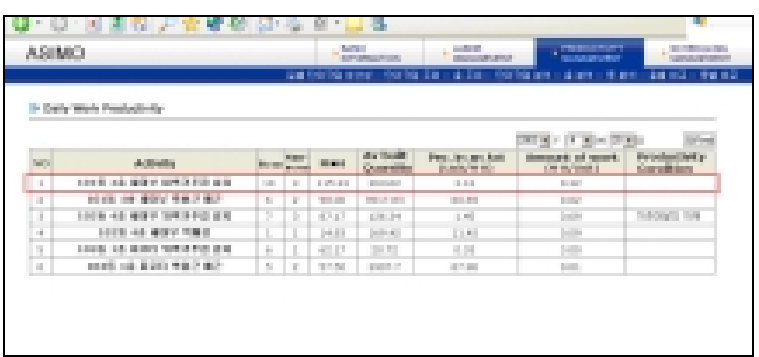

Figure 10. Screen of the Productivity of Activities Performed on Specific Date

The rate of progress represents the percent $(\%)$ of the working process. To calculate the rate of progress, the following process is required.

- Calculate a worker's working time by an activity (the planned amount of work in an activity $\times$ the planned duration of work in an activity(MH/unit)).

- Sum up the work durations for the activities by floors and buildings.

- Assign a weighted value to each activity regarding the rate of work duration in an activity to the sum of work durations for activities, by floors and buildings.

- Calculate the rate of progress(the weighted value $x$ the amount performed work).

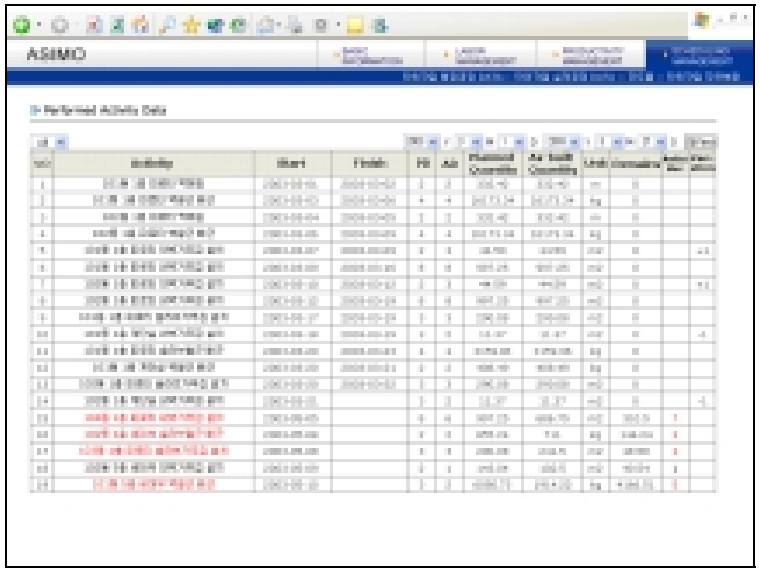

Figure 11. Screen of the Historical Data for the Scheduling Managment

Fig. 12 shows the screen of the progress rate for buildings. This screen illustrates that on April 28, the progress rate of the work on the fourth floor, No.101, is $40.89 \%$ and that in this building is $34.13 \%$. Therefore, progress rate data can be useful for the site engineer to easily understand the work progress status by floors and buildings.

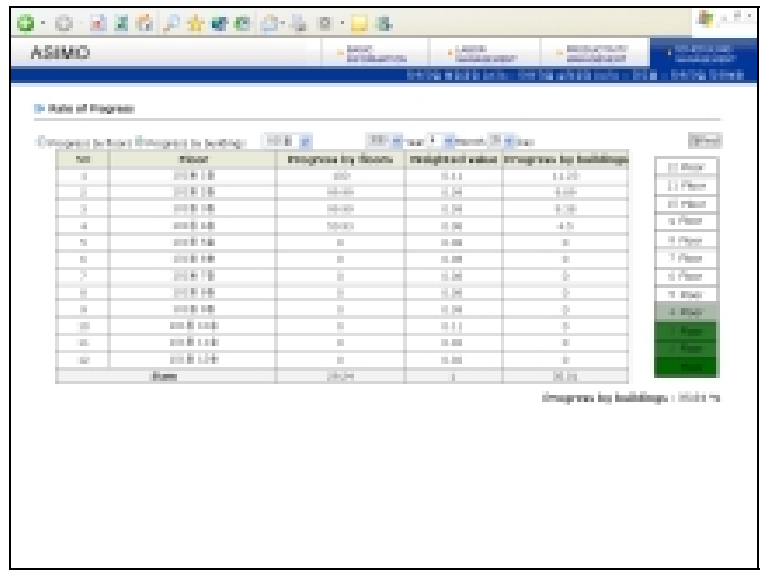

Figure 12. Screen of the Rate of Progress by Buildings

\section{CONCLUSION}

The ASIMO system developed through this research can collect data on the worker's time in office and time out of office, the workers' working time input in activities as well as the amount of work performed in a day. These data can not be only historical data, which could be applied in the labor, productivity, scheduling management, but also important data which could be used to analyze the result of project management. Furthermore, the ASIMO system would be better than the existing system because the ASIMO system is more accurate 
in analyzing a situation, comparing 'as planned' with 'as built' of the construction project and providing similar future projects with useful data. In this paper, the conclusions are as follows:

1) To find problems and to present a solution related to the structure work of an apartment buildings, several interviews with site managers were performed. Important factors to collect and analyze data on the worker's time in office and time out of office, the workers' working time input in activities and the amount of work performed in a day were determined.

2) A methodology based on IT tools such as the PDA and barcode has been proposed to collect data on workers' working time in each activity and the amount of performed work.

3) An algorithm, which is based on the data on workers' attendance, working time in each activity, and the amount of performed work, was developed to integrate the management of labor, productivity and scheduling. The ASIMO system has been developed by designing the UI on the PDA and the PC, which was implemented on the basis of the database modeling.

4) The data of 4 apartment buildings on which the structure work had been performed were collected and the result of application of the field data shows that the developed ASIMO system is useful for construction management (labor management, productivity management, scheduling management).

\section{Acknowledgements}

This work has been supported by the Korea Science and Engineering Foundation (KOSEF) under Grant No. R01-2001-000-00449-0.

\section{REFERENCES}

[1] Kang, K. and Kim, H. (1995), "A study on the field management process with bar-code system", Proceeding of Architectural Institute of Korea, Spring Conference, Vol.15, pp.689-694.

[2] Lee, H., Song, H., Go, S., Moon, J. and Go, I. (2000), "Development of the Program for Construction Processing Information System", Journal of architectural Institute of Korea, Vol.13, pp.62-68.

[3] Lim, H. (2000), “A study on the development of a system to improve the labor field attendance management and on the application of the system in the field", Daelim technical note, spring, pp.62-68.

[4] BRE, "Calibre 2000", CD Rom for presentation 2000.

[5] Lin, Y. and Tserng (2001), "A Model of Supply Chain Management for Construction Using Information Technology", The 18th ISARC Proceeding, Vol.10, No12, pp.141-146. 